\title{
SISTEMA RADICULAR E DESENVOLVIMENTO DE PLANTAS CÍTRICAS PROVENIENTES DE VIVEIRO TELADO E ABERTO ${ }^{1}$
}

\author{
ANTONIO CARLOS DAVOGLIO JUNIOR ${ }^{2}$, IVAN BORDIN ${ }^{3}$, CARMEN SILVIA VIEIRA JANEIRO NEVES ${ }^{4}$
}

\begin{abstract}
RESUMO - O trabalho teve como objetivo avaliar o sistema radicular e o desenvolvimento vegetativo de plantas cítricas, provenientes de mudas produzidas em sistema de viveiro aberto e de telado. A avaliação das raízes foi realizada pela escavação de seis trincheiras para obtenção de imagens digitais das raízes que foram avaliadas pelo programa SIARCS 3.0. Para avaliação do desenvolvimento vegetativo, foram selecionadas 20 plantas. O delineamento estatístico utilizado foi o inteiramente casualizado, e os dados obtidos foram analisados pelo teste t de Student. As plantas provenientes de mudas de viveiro aberto foram superiores às plantas de telado na distância efetiva do sistema radicular, na entrelinha de plantio e no total geral de raízes. O diâmetro e o volume da copa foram superiores para as plantas provenientes de mudas de viveiro aberto em relação às plantas de telado.
\end{abstract}

Termos para Indexação: citros, propagação, raiz.

\section{ROOT SYSTEM AND DEVELOPMENT OF CITRUS PLANTS ORIGINATED FROM OPEN AND PROTECTED NURSERY SYSTEMS}

\begin{abstract}
This research had as objective to evaluate the root system and development of citrus plants, originated from open and protected nursery systems. The roots were evaluated by the trench profile method with six replications for each nursery system, applying the SIARCS 3.0 software to determine root amount and distribution. Twenty plants were selected to evaluate vegetative development. A randomized design and the test $t$ of Student were used for statistical analysis. The plants originated from open nursery system were superior to those from screen house regarding the root effective distance in the inter-rows and total amount of roots. The diameter and volume of the canopy were superior for plants originated from open nursery system.
\end{abstract}

Index terms: citrus, propagation, root.

\section{INTRODUÇÃO}

A muda cítrica de qualidade é um dos fatores mais importantes na implantação de um pomar comercial devido ao caráter perene da cultura dos citros. Tradicionalmente, a produção de mudas cítricas consistia na semeadura de porta-enxertos em canteiros, onde as plantas permaneciam até atingirem o tamanho aproximado de $10 \mathrm{~cm}$. Essas plantas eram transplantadas para o viveiro a céu aberto, onde permaneciam de seis a oito meses, até receberem a enxertia da copa. Quando atingiam a altura de $60 \mathrm{a} 70 \mathrm{~cm}$, as mudas eram retiradas do campo com auxílio de ferramentas de corte, obtendo-se mudas de torrão, que eram embaladas em sacos de estopa ou embalagens de pinho ou plásticas (Teófilo Sobrinho, 1991), caracterizando um sistema de produção de mudas totalmente aberto.

$\mathrm{O}$ aumento da incidência de doenças causadas por vírus, viróides, fungos, bactérias e nematóides, destacando-se a clorose variegada dos citros (CVC), doença associada à bactéria Xylella fastidiosa, cujos vetores são as cigarrinhas da família Cicadellidae, resultou na recomendação de não se utilizarem mudas provenientes do sistema aberto, por se constituírem foco disseminador desses problemas fitossanitários. Com isso, passou-se a utilizar o sistema telado para produção de mudas cítricas, que consiste na utilização de tubetes com substratos e água isentos de patógenos, sob ambiente protegido com telas antiafídeos (Borges et al., 2000).

Este novo sistema de produção de mudas cítricas começou a ser adotado no final dos anos 90 e foi consolidado em janeiro de 2003 , com a proibição da produção e comercialização de mudas cítricas fiscalizadas em ambiente aberto, de acordo com as normas para produção, estocagem, comércio, transporte e plantio de mudas cítricas no Estado de São Paulo, instituídas pela Agência de Defesa Agropecuária do Estado de São Paulo (ADAESP) (Carvalho, 2003).

Uma muda de qualidade, além de ser isenta de patógenos, deve apresentar quatro características fundamentais: variedade copa, variedade porta-enxerto, conformação da muda e vigor, a fim de suportar o estresse do transplantio ao campo, de modo que a planta proporcione boa produção de frutos e longevidade (Moreira, 1995). Para que as plantas produzidas em escala comercial tenham bom desenvolvimento, é essencial que se tenha conhecimento sobre a distribuição e qualidade das raízes, pois estas informações podem auxiliar em práticas de manejo, como espaçamento de plantio, culturas intercalares, manejo do solo, irrigação e otimização da distribuição de adubos (Neves et al., 2001).

De acordo com inspeções realizadas em março de 2006 pelo FUNDECITRUS (2006), dos 509 viveiros do Estado de São Paulo, 508 são telados, e na ocasião eram responsáveis pela produção de 11.360.797 mudas cítricas, o que representa 99,97\% das mudas em formação no Estado. Assim, considerando a crescente inclusão das mudas de telado nos pomares paulistas, faz-se necessário avaliar o desempenho destas mudas a campo. Dessa forma, o presente trabalho teve como objetivo avaliar o sistema radicular e o desenvolvimento vegetativo de plantas cítricas provenientes de viveiro telado e aberto.

\section{MATERIAL E MÉTODOS}

O experimento foi realizado no Município de Cafelândia - SP, coordenadas $21^{\circ} 48^{\prime} \mathrm{S}$ e $49^{\circ} 36^{\prime} \mathrm{W}$, com $467 \mathrm{~m}$ de altitude, precipitação média anual de $1.200 \mathrm{~mm}$ e temperatura média anual de $24,0^{\circ} \mathrm{C}$. O solo é classificado como Latossolo distrófico de textura franca (EMBRAPA, 1999). Para a caracterização do solo, foram coletadas aleatoriamente quatro amostras, em quatro profundidades $(0-25 ; 25$ 50; 50-75 e 75-100 cm), na linha e na entrelinha de plantio, cujas análises físicas (EMBRAPA, 1997) apresentaram valores que variaram de 0,10$0,15 \mathrm{~m}^{3} \mathrm{~m}^{-3}$ de macroporosidade, $0,31-0,34 \mathrm{~m}^{3} \mathrm{~m}^{-3}$ de microporosidade, $0,41-0,48 \mathrm{~m}^{3} \mathrm{~m}^{-3}$ de porosidade total e $1,11-1,29 \mathrm{~kg} \mathrm{dm}^{-3}$ de densidade do solo. As análises químicas (IAPAR, 1992) apresentaram valores de 4,5-4,9 de pH em CaCl2 (0,01 $\left.\mathrm{mol} \mathrm{L}^{-1}\right) ; 0,5-1,0 \mathrm{~g} \mathrm{dm}^{-3}$ matéria orgânica; $0,2-1,9 \mathrm{mg} \mathrm{dm}^{-3} \mathrm{de} \mathrm{P} ; 0,02-0,19 \mathrm{cmol}_{\mathrm{c}} \mathrm{dm}^{-3} \mathrm{de} \mathrm{K}^{+} ; 0,8-1,3 \mathrm{cmol}_{\mathrm{c}} \mathrm{dm}^{-3} \mathrm{de}$

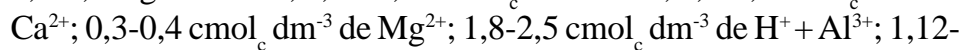

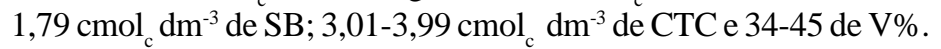

\footnotetext{
${ }^{1}$ (Trabalho 020-2006). Recebido: 02-03-2006. Aceito para publicação: 30-05-2006.

${ }^{2}$ Acadêmico de Agronomia, UEL.

${ }^{3}$ Engenheiro Agrônomo, Doutorando em Agronomia, Universidade Estadual de Londrina (UEL), e-mail: ivanbordin @ hotmail.com.

${ }^{4}$ Engenheiro(a) Agrônomo(a), Doutor(a), Professor(a) Associado(a), Departamento de Agronomia, UEL, C.P. 6001, CEP 86051-990, Londrina-PR, e-mail: csvjneve@uel.br. Bolsista em Produtividade, CNPq. Autora para correspondência.
} 
As plantas avaliadas pertenciam a um pomar comercial formado por laranja 'Pêra' (Citrus sinensis (L) Osb.) sobre limão 'Cravo' (Citrus limonia Osb.), que foi implantado em outubro de 1999, em área previamente ocupada por pecuária de corte extensiva. O preparo do solo foi realizado com arações, gradagens e abertura de sulcos com $30 \mathrm{~cm}$ de profundidade para o plantio das mudas, no espaçamento de 7,5 m x 4,0 m. As mudas foram adquiridas no viveiro comercial CITROGRAF, situado no Município de Conchal - SP, sendo oriundas de dois sistemas distintos de produção: sistema em viveiro aberto a campo com mudas de torrão e sistema de produção em tubetes sob viveiro telado. As plantas receberam os mesmos tratos culturais, com o manejo de plantas daninhas na linha de plantio com herbicida glifosate e nas entrelinhas braquiária (Brachearia decumbes) com roçadas periódicas. As adubações seguiram as recomendações do GRUPOPAULISTADEADUBAÇÃOECALAGEMDECÍTRUS (1994) e os tratamentos fitossanitários foram realizados sempre que necessário.

Em março de 2004, foram realizadas as avaliações. Para o sistema radicular, foi utilizado o método do perfil (Böhm, 1979), sendo abertas seis trincheiras para cada tratamento, inicialmente com retroescavadeira, e o acabamento, realizado com auxílio de pás, enxadões e pás-de-corte. As trincheiras ficaram perpendiculares à linha de plantio, a $10 \mathrm{~cm}$ do tronco das árvores, com comprimento de $2 \mathrm{~m}$ na linha de plantio e $3,75 \mathrm{~m}$ na entrelinha, com profundidade de 1 $\mathrm{m}$. As raízes foram expostas com escarificador manual em forma de rolo com pregos sem cabeça e coloridas com tinta branca. Afixando- se ao perfil do solo uma moldura de madeira dividida por fios de náilon em quadrículas de $25 \times 25 \mathrm{~cm}$, foram obtidas imagens de cada quadrícula com câmera digital. As imagens foram avaliadas pelo Sistema Integrado de Análise de Raízes e Cobertura do Solo (SIARCS 3.0) (Crestana et al., 1994), obtendo-se o comprimento de raízes. As avaliações foram realizadas em relação à distribuição das raízes em profundidade e distância do tronco, juntamente com suas respectivas profundidades e distâncias efetivas, que correspondem à concentração de $80 \%$ do sistema radicular (Klar, 1991).

Para avaliação do desenvolvimento vegetativo, foram sorteadas 20 plantas por tratamento, medindo-se a altura e o diâmetro médio da copa, resultante da média entre as medidas perpendiculares e no sentido da linha de plantio, utilizando-se de régua de madeira graduada. Assim, com a altura e o diâmetro médio, foi calculado o volume da copa (Mendel, 1956). O perímetro do tronco foi obtido com uma fita métrica a cinco centímetros acima da enxertia. O delineamento estatístico utilizado foi o inteiramente casualizado, submetendo-se os dados ao teste $\mathrm{t}$ de Student, com $5 \%$ de probabilidade de erro.

\section{RESULTADOS E DISCUSSÃO}

Para a quantidade de raízes em profundidade na linha de plantio, não foi possível constatar diferenças entre os tratamentos em nenhuma das profundidades avaliadas, enquanto, na entrelinha, as plantas provenientes de mudas do sistema aberto apresentaram mais raízes do que as produzidas pelo sistema de telado na profundidade de 75-100
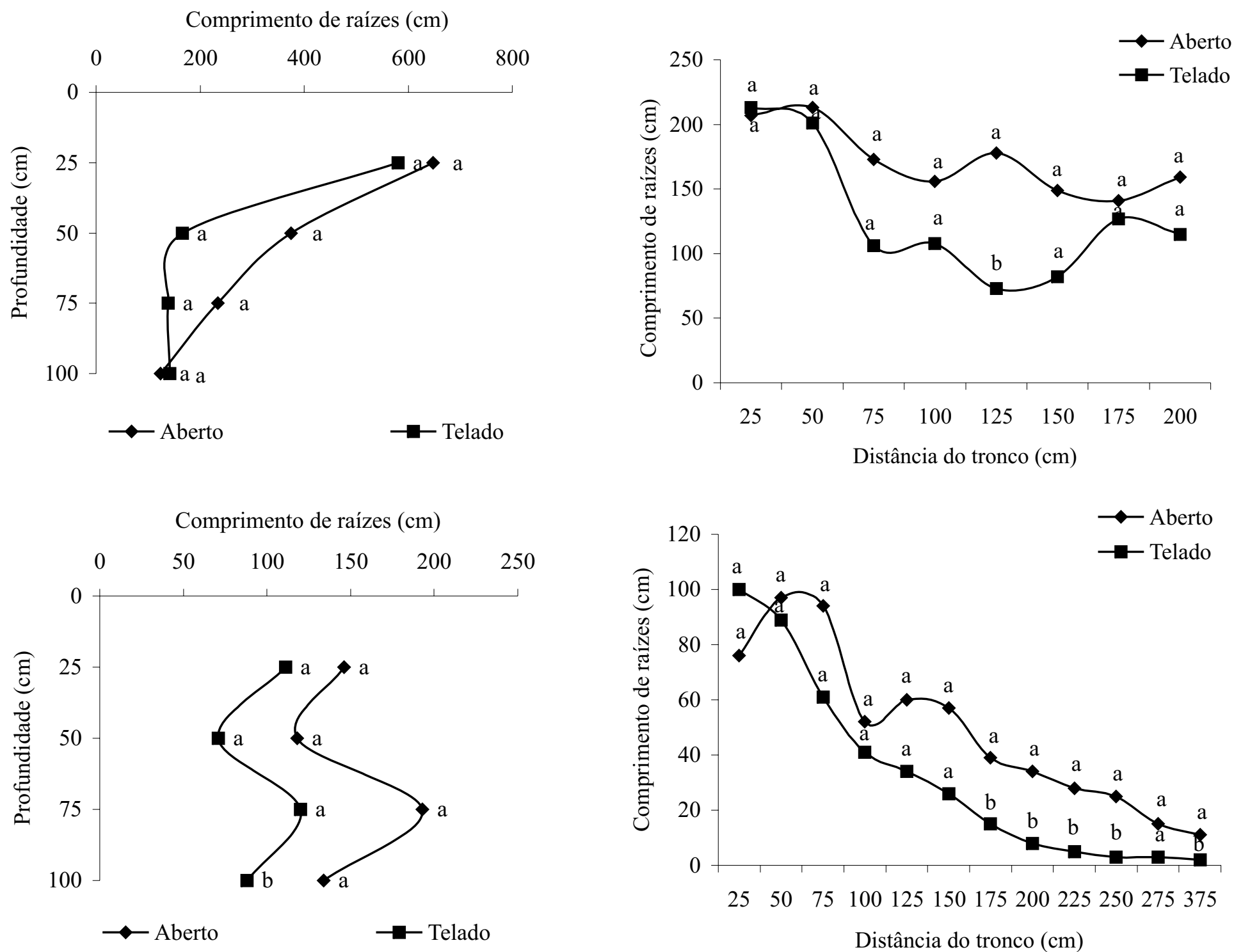

FIGURA 1 - Comprimento de raízes de laranja 'Pêra' sobre limão 'Cravo' provenientes dos sistemas de produção de mudas em viveiro aberto e telado, nas diferentes profundidades (A) e distâncias do tronco (B), para linha e entrelinha de plantio. Médias seguidas da mesma letra não diferem entre si, pelo teste $\mathrm{t}$ de Student, a $5 \%$ de probabilidade. 
cm, não se diferenciando nas demais profundidades (Figura 1).

Ambos os tratamentos apresentaram expressiva quantidade radicular em profundidade, principalmente na entrelinha, onde a profundidade de $50-75 \mathrm{~cm}$ apresentou maior comprimento radicular que a $0-25$ e $25-50 \mathrm{~cm}$. Isto pode ser explicado pelas características físicas do solo, pois, de acordo com Grabe \& Siemer (1968), o limite crítico de aeração que reduz sensivelmente o crescimento de raízes é de $0,10 \mathrm{~m}^{3} \mathrm{~m}^{-3}$ de porosidade responsável pela aeração (macroporosidade), enquanto as densidades do solo entre 1,30 a 1,5 $\mathrm{kg} . \mathrm{dm}^{-3}$ podem restringir o desenvolvimento radicular (Silva \& Rosolem, 2001; Müller et al., 2001). No presente estudo, os valores obtidos por estes atributos do solo não foram limitantes ao crescimento radicular em profundidade. Assim, em função da distribuição das raízes em profundidade, ambos os tratamentos estariam em boas condições para suportar pequenos períodos de estresse hídrico (Mazza et al., 1994; Neves et al., 1998).

Com relação à quantidade de raízes por distância do tronco (Figura 1), o tratamento do sistema aberto foi superior ao telado na distância de 100-125 cm na linha de plantio, não havendo diferenças nas demais distâncias, enquanto, na entrelinha, a superioridade do sistema aberto sobre o sistema telado ficou evidenciada desde a distância de $150-175 \mathrm{~cm}$ até a distância de $225-250 \mathrm{~cm}$ e novamente na última distância, a $275-375 \mathrm{~cm}$. Esta superioridade demonstra um maior potencial de exploração do solo que pode refletir-se em maior absorção de nutrientes provenientes da ciclagem da braquiária na entrelinha e principalmente maior aproveitamento da adubação química (Neves et al., 2001).

Para profundidade efetiva do sistema radicular (Tabela 1), não foi constatada diferença entre os tratamentos, tanto na linha como na entrelinha. As profundidades efetivas observadas na linha e entrelinha, para ambos os tratamentos, variaram de 57 a $63 \mathrm{~cm}$, concordando com os resultados encontrados por Neves et al. (2004) ao trabalharem com lima ácida 'Tahiti' sobre vários porta-enxertos, com 11 anos de idade, em Latossolo argiloso, a profundidade de 1,0 $\mathrm{m}$, o que pode indicar que, aos quatro anos e meio de idade, o sistema radicular já se estabeleceu em profundidade.

Com relação às distâncias efetivas (Tabela 1), foi constatada a superioridade do sistema aberto sobre o telado na entrelinha de plantio, evidenciando a melhor exploração horizontal do solo em função do maior vigor das mudas provenientes de viveiros abertos.

TABELA 1 - Variáveis referentes ao sistema radicular de laranja 'Pêra' sobre limão 'Cravo' provenientes dos sistemas de produção de mudas em viveiro aberto e telado.

\begin{tabular}{lrr}
\hline \multicolumn{1}{c}{ Variáveis } & Aberto & Telado \\
& \multicolumn{2}{c}{$\mathrm{cm}$} \\
\hline Profundidade efetiva na linha & $56,95 \mathrm{a}$ * & $62,82 \mathrm{a}$ \\
Profundidade efetiva na entrelinha & $77,58 \mathrm{a}$ & $78,16 \mathrm{a}$ \\
Distância efetiva na linha & $156,24 \mathrm{a}$ & $152,02 \mathrm{a}$ \\
Distância efetiva na entrelinha & $167,11 \mathrm{a}$ & $106,31 \mathrm{~b}$ \\
Total de raízes na linha & $1381,69 \mathrm{a}$ & $1029,03 \mathrm{a}$ \\
Total de raízes na entrelinha & $592,42 \mathrm{a}$ & $391,32 \mathrm{a}$ \\
Total geral de raízes & $1974,10 \mathrm{a}$ & $1420,35 \mathrm{~b}$ \\
\hline
\end{tabular}

*Médias seguidas da mesma letra na linha, não diferem entre si, pelo teste $\mathrm{t}$ de Student, a $5 \%$ de probabilidade.

TABELA 2 - Desenvolvimento vegetativo de laranja 'Pêra' sobre limão ‘Cravo' em plantas provenientes dos sistemas de produção de mudas em viveiro aberto e telado.

\begin{tabular}{lcc}
\hline \multicolumn{1}{c}{ Variáveis } & Aberto & Telado \\
\hline Altura da planta $(\mathrm{m})$ & $3,22 \mathrm{a}^{*}$ & $3,15 \mathrm{a}$ \\
Perímetro do tronco $(\mathrm{cm})$ & $40,95 \mathrm{a}$ & $37,45 \mathrm{a}$ \\
Volume da copa $\left(\mathrm{m}^{3}\right)$ & $18,94 \mathrm{a}$ & $16,89 \mathrm{~b}$ \\
Diâmetro da copa $(\mathrm{m})$ & $3,35 \mathrm{a}$ & $3,19 \mathrm{~b}$ \\
\hline
\end{tabular}

*Médias seguidas da mesma letra na linha, não diferem entre si, pelo teste $\mathrm{t}$ de Student, a $5 \%$ de probabilidade.
As plantas de ambos os tratamentos tiveram suas distâncias efetivas entre 152 e $156 \mathrm{~cm}$, na linha, e 106 e 167, cm na entrelinha, estando praticamente todas as distâncias dentro do raio médio da copa, que ficou entre 1,60 e 1,67 m (Tabela 2). Estes resultados reforçam as recomendações de adubação e calagem para plantas com mais de três anos, que indicam a aplicação de $2 / 3$ destes insumos sob a projeção da copa e 1/3 fora (GRUPO PAULISTADEADUBAÇÃO ECALAGEM PARACITROS, 1994).

Para o total de raízes na linha e entrelinha de plantio, não foi constatada diferença; no entanto, para o total geral de raízes, o sistema aberto foi superior ao telado. Estes resultados evidenciam que, além de uma distribuição mais distante do tronco na entrelinha, também existem mais raízes no total geral, corroborando a hipótese de que o maior desenvolvimento radicular das mudas convencionais em relação às de telado se deve ao maior vigor da muda no momento do plantio. Segundo Teófilo Sobrinho (1991) e Borges et al. (2000), a produção de mudas de viveiros abertos pode levar de 18 a 24 meses da semeadura dos porta-enxertos até o plantio definitivo no campo, além do fato de que o sistema radicular se desenvolve no solo sem restrições antes de ser cortado e condicionado em um volume aproximado de 4 litros. Já a produção de mudas de telado leva de 11 a 12 meses, sendo o desenvolvimento em recipientes que restringem o espaço a ser explorado pelas raízes em um volume aproximado de 2 litros.

Para a altura da planta e o perímetro do tronco, não foi possível verificar diferenças entre os tratamentos avaliados, enquanto o diâmetro e o volume da copa do tratamento em viveiro aberto foram superiores ao tratamento telado. Estes dados evidenciam a existência da correlação entre o desenvolvimento da parte aérea e do sistema radicular. Um fator que deve ser considerado é que, na cultura dos citros, o crescimento da parte aérea e das raízes segue um ritmo alternado. Bevington \& Castle (1985) constataram que, mesmo não havendo fatores limitantes em relação aos atributos do solo, o crescimento da parte aérea é cíclico, alternando-se com o crescimento das raízes. Observaram também, em plantas de laranjeira 'Valência' sobre limoeiro 'Rugoso' e citrange 'Carrizo', que a redução no crescimento da parte aérea ocorreu na mesma proporção do aumento da taxa de crescimento do sistema radicular.

Apesar de o trabalho evidenciar maior desenvolvimento radicular e da parte aérea das plantas provenientes de mudas de viveiro aberto em relação às mudas de telado, deve-se tomar cuidado com possíveis interpretações dos resultados, devido ao fato de as plantas cítricas terem sido avaliadas aos quatro anos e meio de idade e só expressarem seu potencial produtivo entre oito e dez anos (Teófilo Sobrinho, 1991).

\section{AGRADECIMENTOS}

Os autores agradecem aos Srs. Antônio Carlos Davoglio e Nildo Fernando Davoglio, pelas condições proporcionadas para a realização do trabalho.

\section{CONCLUSÕES}

1. Aos quatro e meio anos de idade, as plantas provenientes de mudas de viveiro aberto foram superiores às plantas de telado na distância efetiva do sistema radicular na entrelinha de plantio e total geral de raízes.

2. O diâmetro e o volume da copa foram superiores para as plantas provenientes de mudas de viveiro aberto em relação às plantas de telado.

\section{REFERÊNCIAS}

BEVINGTON, K. B.; CASTLE, W.S. Annual root growth pattern of young citrus trees in relation to shoot growth, soil temperature, and soil water content. Journal of the American Society for 
Horticultural Science, Alexandria, v. 110, n. 6, p. 840-845, 1985.

BÖHM, W. Methods of studying root systems. Berlim: Springer Verlag, 1979.188p

BORGES, R. S.; ALMEIDA, F. J.; SCARANARI, C.; MACHADO, M. A.; CARVAlHO, S. A.; COLETTA, F. H. D.; VILDOSO, C. I. A. Programa IAC/EMBRAPA/CNPq de incentivo à produção e difusão de mudas de citros isentas de clorose veriegada dos citros e outras doenças. Laranja, Cordeirópolis, v. 21, n. 1, p. 205224, 2000.

CARVALHO, S. A. Regulamentação atual da Agência de Defesa Agropecuária para a produção, estocagem, comércio, transporte e plantio de mudas cítricas no Estado de São Paulo. Laranja, Cordeirópolis, v.24, n. 1, p. 199-239, 2003.

CRESTANA, A.; GUIMARÃES, M. F.; JORGE, L. A. C.; RALISCH, R.; TOZZI, C. L., TORRES, A.; VAZ, C. M. P. Avaliação da distribuição de raízes no solo auxiliada por processamento de imagens. Revista Brasileira de Ciência do Solo, Viçosa, v. 18, p. 365-371, 1994.

EMBRAPA - Empresa Brasileira de Pesquisa Agropecuária. Manual de métodos de análise de solos. Rio de Janeiro: Embrapa Solos, 1997.212p

EMBRAPA - Empresa Brasileira de Pesquisa Agropecuária. Sistema Brasileiro de Classificação de Solos. Rio de Janeiro: Embrapa Solos, 1999. 412p.

FUNDECITRUS. Viveiros. Araraquara. Disponível em: <http:// www.fundecitrus.com.br>. Acesso em: 11 maio 2006.

GRABE, A. R.; SIEMER, E. F. Effects of bulk density, aggregate size and soil water suction on oxygen diffusion, redox potential and elongation of corn roots. Soil Science Society American Journal, Madison, v. 32 n. 1, p.180-186, 1968.

GRUPO PAULISTADE ADUBAÇÃO E CALAGEM PARACITROS. Recomendações de adubação e calagem para citros no Estado de São Paulo. Laranja, Cordeirópolis, v.15, n. esp, p. 1-27, 1994.

IAPAR - Instituto Agronômico do Paraná. Manual de análise química do solo e controle de qualidade. Londrina: IAPAR, 1992. 40p. (Circular Técnico, 76).
KLAR, A. E. Irrigação: freqüência e quantidade de aplicação. São Paulo: Nobel, 1991. 156p.

MAZZA, J.A.; VITTI, G.C.; PEREIRA, H.S.; MENEZES, G.M.; TAGLIARINI, C.H. Influência da compactação no desenvolvimento do sistema radicular de cítrus: sugestão de método qualitativo de avaliação e recomendações de manejo. Laranja, Cordeirópolis, v.15, n.2, p.263-275, 1994.

MENDEL, K. Rootstock - scion relationship in Shamouth trees on light soil. Ktavim, Rehovot, v. 6, p. 35-60, 1956.

MOREIRA, S. Cavalos para citros em São Paulo. Laranja, Cordeirópolis, v. 16 n. 2, p. 213-233, 1995.

MÜLLER, M. M. L.; CECCON, G.; ROSOLEM, C. A. Influência da compactação do solo em subsuperfície sobre o crescimento aéreo e radicular de plantas de adubação verde de inverno. Revista Brasileira de Ciência do Solo, Viçosa, v. 25, n. 3, p. 531-538, 2001.

NEVES, C. S. V. J.; BORGES, A. V.; KANAI, H. T.; PRETE, C. E. C.; CARPENTIERI-PÍPOLO, V. Distribuição do sistema radicular da aceroleira. Revista Brasileira de Fruticultura, Jaboticabal, v. 23, n. 1, p. 112-115, 2001.

NEVES, C. S. V. J.; DECHEN, A. R.; FELLER, C.; ABI SAAB, O. J. G.; PIEDADE, S. M. S. Efeito do manejo do solo no sistema radicular de tangerineira 'Poncã' enxertada sobre limoeiro 'Cravo' em Latossolo Roxo. Revista Brasileira de Fruticultura, Cruz das Almas, v. 20, n. 2, p. 246-253,1998.

NEVES, C. S. V. J.; MURATA, I. M.; STENZEL, N. M. C.; MEDINA, C. C.; BORGES, A. V.; OKUMOTO, S. H.; LEE, R. H. CH.; KANAI, H. T. Root distribution of rootstocks for 'Tahiti' lime. Scientia Agricola, Piracicaba, v. 61, n. 1, p. 94-99, 2004.

SILVA, H. R.; ROSOLEM, C.A. Crescimento radicular de espécies utilizadas como cobertura decorrente da compactação do solo. Revista Brasileira de Ciência do Solo, Viçosa, v. 25, n. 2, p. 253260, 2001

TEÓFILO SOBRINHO, J. Propagação de citros. In: RODRIGUEZ, O.; VIÉGAS, F. C. P.; POMPEU JÚNIOR, J.; AMARO, A. A. Citricultura brasileira, 2. ed. Campinas: Fundação Cargill, 1991. v.1, p. 281-301. 